\section{Keeping up with upkeep}
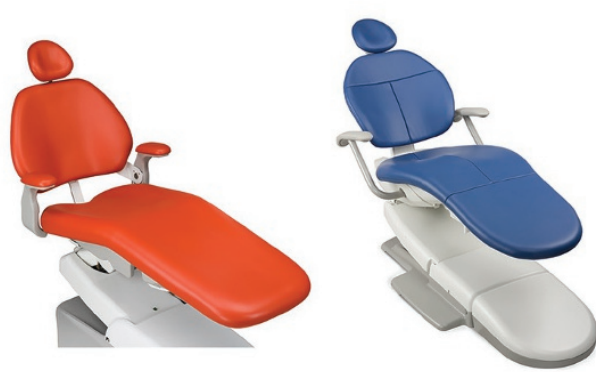

A-dec chairs are world-renowned for their reliability. Each component of every chair, light or delivery system has been rigorously tested in the A-dec factory to ensure it performs in circumstances beyond anything that might be reasonably experienced in the dental surgery.

On top of this, A-dec products have very reasonable life costs and will remain a solid investment over the length of their expected lifespan. This is of the utmost importance as professionals do not want to be beleaguered by expensive maintenance costs and upkeep fees over the long period of time that a modern dental chair can be expected to operate.

Most importantly, A-dec works closely with a number of UK retailers, creating a
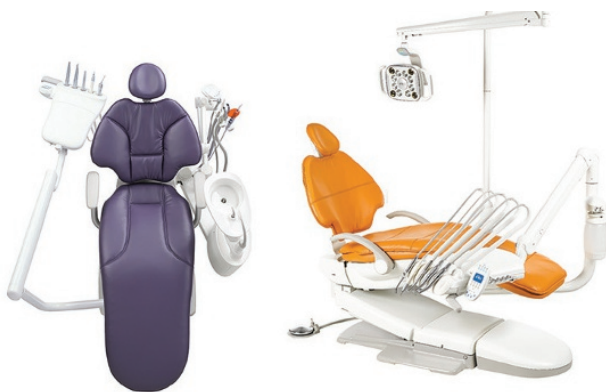

strong and indispensable support network. Retailer engineers have been certified by A-dec's experienced team, allowing them to easily service or repair A-dec products with genuine parts and provide the highest standard of maintenance and repair.

With A-dec's support, these engineers will also be able to establish the A-dec planned preventative maintenance programme, which is the most effective way of ensuring equipment is kept in optimum condition for longer.

To find out more about A-dec equipment and how it could help you keep up with your upkeep, contact the friendly UK team today. Visit www.a-dec.co.uk or call 0800233285.

\section{Extend your skills and competency this autumn}

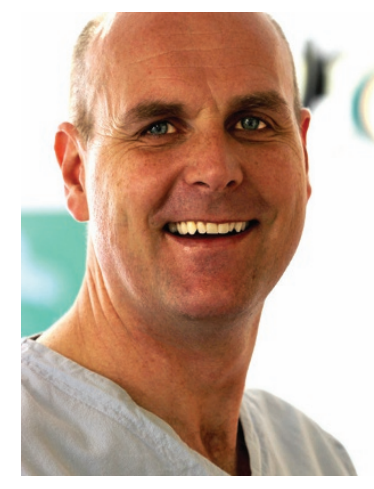

At this year's Dental Showcase there will be a range of lectures for you to attend, all guaranteed to extend your skills and competency with practical knowledge that you can reapply in practice.

The Dental Update Theatre will host a range of experts, all of whom offer practical guidance on a range of clinical and non-clinical topics.

Opening the session on Friday and Saturday will be Dr Louis Mackenzie (pictured), a dentist and lecturer at Birmingham School of Dentistry, who will be reviewing the latest materials, equipment and clinical techniques for predictable and enjoyable aesthetic restorative dentistry.

Professor Ed Lynch will start the afternoon session on the Friday by examining the 'One Visit Crown' (OVC) from Rhondium. He will explain how the OVC combines a preformed occlusal layer and an un-cured layer of hybrid ceramic. This futuristic concept obviates the need for impressions, dental labs and $\mathrm{CAD} / \mathrm{CAM}$ machines.

In the last session on Friday afternoon Luke Moore and Paul Wilkinson, directors from Dental Elite, will review market movements and its impact on practice valuations.

Dr Ben Atkins will be exploring how the evolution of oral healthcare has given us better tools than ever to meet patients' needs. He will explain how he has overhauled his high need patients' oral healthcare, to change their lives for the better.

These are just some of the lectures taking place. For the full programme visit www. dentalshowcase.com.

\section{Introducing a new online community}

As part of its continued commitment to providing you with solutions and support that meets your needs, Carestream Dental is delighted to have recently launched a new online community - The Exchange.

This innovative portal allows CS R4+ users to come together and share top tips, as well as ask questions about how to get the very most out of their practice management software.

Signing up is so simple and it's completely free. All you need to do is visit community.carestreamdental.com to activate access for your entire team.

Dedicated to making your life easier through cutting-edge technologies and continuous support services, Carestream Dental is thrilled to offer this latest resource for all its customers.

For more information contact Carestream Dental on 08001699692 or visit www.carestreamdental.co.uk.

\section{Making the most of employee benefits}

An increasing number of employers in the UK are offering their employees dental benefits what are you doing to take advantage of this?

If the answer is 'nothing' then it's time to get in contact with Munroe Sutton.

By signing up free to Munroe Sutton, you will be entered into a vast referral network of businesses that offer the Healthy Discounts scheme to their employees. When any of these employees need dental treatment, they are directed to a Munroe Sutton-partnered practice, to receive the first-rate service they need at a great price.

This means that by doing nothing except accepting Healthy Discounts members, you will become a hub for referred patients. All you need to do is offer the standard 20\% discount on included treatments.

What's more, as part of Munroe Sutton, you will also receive expert marketing advice from the team, unrivalled client support and free enrolment to one of the UK's largest networks of healthcare, insurance and business institutions.

To find out more about the Healthy Discounts scheme, call 08082343558 or visit www.munroesutton.co.uk. 